\title{
Electrochemical Study of Penicillin-G as a Corrosion Inhibitor for Fe-19Cr Stainless Steel in Hydrochloric Acid
}

\author{
Samir Bo Uakkaz, ${ }^{a}$ Ridha Zerdoumi, ${ }^{b}$ Kafia Oulmi, ${ }^{a, *}$ \\ Dhaouadi Mellahi, ${ }^{a}$ George M. Andreadis ${ }^{c}$ \\ ${ }^{a}$ Laboratory of Chemistry and Environmental Chemistry, Department of Chemistry, Faculty of \\ Science, University of Batna, Algeria \\ ${ }^{b}$ Laboratory of Electrochemistry, Molecular Engineering and Red-Ox Catalysis (LEMIRC), \\ Faculty of Technology, University of Setif-1, 19000 Setif, Algeria \\ ${ }^{c}$ Department of Mechanical Engineering, School of Engineering, University of Thessaly, \\ Pedion Areos, 38334 Volos, Greece
}

Received August 26, 2016; accepted March 14, 2017

\begin{abstract}
In the present work, the inhibitory properties and the adsorption mechanism of penicillin $\mathrm{G}$ for the corrosion of $\mathrm{Fe}-19 \mathrm{Cr}$ stainless steel in an $\mathrm{HCl}$ solution were investigated. Electrochemical methods, the open circuit potential (OCP) and the current potential curves $(I-V)$ were used. The inhibition efficiency of the penicillin $\mathrm{G}$ was calculated and found to be up to $60 \%$ for hydrochloric acid. The adsorption of this inhibitor was described by Langmuir isotherm, and the negative values of Gibbs energy indicate the nature of interactions between the inhibitor molecules and the metal surface.
\end{abstract}

Keywords: Electrochemical methods; stainless steel; inhibitor; adsorption isotherm.

\section{Introduction}

Stainless steel is commonly used in drinking water pipeline systems [1-4] and dental alloys [5-7], due to its inherent corrosion resistance. Metal corrosion is a major industrial problem, and it has attracted the attention of researchers worldwide [1-20]. The use of inhibitors has been found to be one of the best practical methods available for the protection of metals against corrosion, especially in acidic media [8-9, 23]. Inhibitors are substances (or a combination of substances) added in a very low concentration to treat the surface of a metal that is exposed to a corrosive environment, in order to terminate or reduce its corrosion rate [8]. The most efficient corrosion inhibitors are organic compounds containing electronegative functional groups and $\pi$ electrons in their triple or

\footnotetext{
*Corresponding author. E-mail address: kafia29@gmail.com
} 
conjugated double bonds, and/or inorganic compounds, such as chromate, dichromate, nitrite, and so on [10-13]. The initial report of corrosion inhibition by organic inhibitors is attributed to Speller [11], who examined the corrosion inhibition of scaled water pipes in $\mathrm{HCl}$. Since then, many organic and inorganic compounds that are added to corrosive fluids have been investigated for this purpose [10-23]. It is reported that organic materials, such as polymers or macromolecules having $-\mathrm{OH},-\mathrm{COOH},-\mathrm{NH}_{2}$, etc., functional groups, were found to be corrosion inhibitors in different corrosive environments. Important corrosion inhibition efficiencies that are observed using conducting polymers are not only due to the presence of $\pi$-electrons, but also to their larger molecular size, which ensures greater coverage of the metallic surface [12]. Thus, the efficiency of an organic compound as a successful inhibitor is mainly due to its ability to be adsorbed onto the metal surface. Many studies show that a wide range of compounds have been successfully investigated as potential inhibitors for the corrosion of metals $[11,23]$. However, the use of these compounds has been lately questioned, due to the several negative effects they have caused in the environment. Thus, the development of better inhibitors of natural source and non-toxic type has been considered to be more important and desirable. Due to their natural origin, as well as their non-toxic characteristics and negligible negative impacts on the aquatic environment, drugs (chemical medicines) seem to be ideal candidates to replace traditional toxic corrosion inhibitors [14-16, 26]. Recently, the use of antibiotics and other drugs has been investigated, and their inhibition efficiencies have been linked to their heterocyclic nature [16]. The unique advantage of using natural products for the inhibition of metal corrosion is that they are environmentally friendly. Similarly, Eddy and Odo Emelam [14] reported that most heterocyclic drugs are environmentally friendly, and can favorably compete with natural products. Gokhan Gece [16] presented the contributions on the use of drugs as corrosion inhibitors for different metals in recent years.

Various natural products were used as corrosion inhibitors in different applications [17-18, 23]. The obtained data showed that plant extracts could serve as effective environmentally friendly 'green' corrosion inhibitors. It is interesting to note that amino acids are components of living organisms, and are precursors for protein formation. Several researchers have investigated the inhibitory potential of some amino acids, and these compounds were reported as green corrosion inhibitors for many metals in various aggressive media [19-23].

The aim of the present work is to study the inhibitory properties and the mechanism of the penicillin $\mathrm{G}$ adsorption for the corrosion of $\mathrm{Fe}-19 \mathrm{Cr}$ in an aqueous $\mathrm{HCl}$ solution. The used electrochemical methods during the experiments are open circuit potential versus time $(V-t)$ and polarization curves $I-V$. Tafel plot was applied to determine the electrochemical parameters (corrosion current $i_{\text {corr, }}$, corrosion potential $\mathrm{E}_{\mathrm{corr}}$, inhibiting effect $(\mathrm{IE} \%)$, polarization resistance $(R \mathrm{p})$, etc.). 


\section{Electrochemical set up and measurements \\ Solutions and materials}

Corrosive solutions

Different concentrations of hydrochloric acid solutions were prepared from the $\mathrm{HCl}$ mother solution of analytical grade by dilution with distilled water.

\section{Inhibitor}

Penicillin $G$ was purchased from a medicine shop, with the trade name Penicillin sodium, and used without further purification. Penicillin G (Fig.1) is an N-S heterocyclic compound containing four oxygen atoms, two nitrogen atoms and one sulfur atom. Thus, it is expected to act as a good inhibitor. The range of the inhibitor concentrations was from 20 to $100 \mathrm{ppm}$.

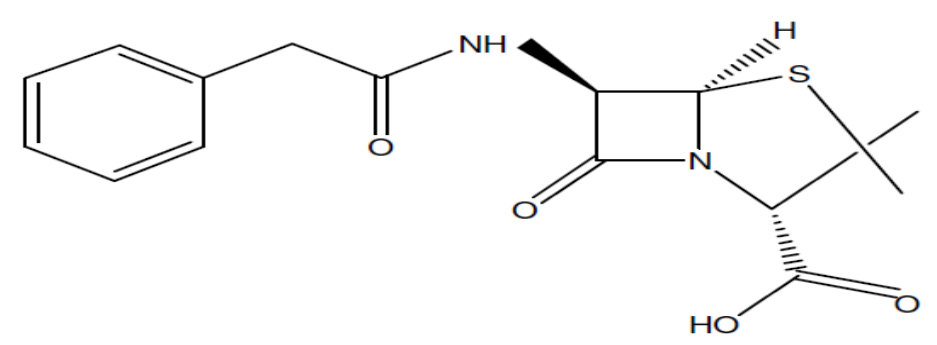

Figure 1. Chemical structure of penicillin $\mathrm{G}[14,16,26]$.

\section{Materials}

Test specimens were cut from a commercially available mild steel rod (wt $\%$ composition: $19 \mathrm{Cr}, 10 \mathrm{Ni}, 4 \mathrm{Mo}$, and the remainder, iron). They were washed with water, rinsed with acetone, washed again thoroughly with doubly distilled water for several times, and used as the working electrode in electrochemical measurements. The potentiodynamic polarization curves were obtained for Fe19Cr in a naturally aerated $\mathrm{HCl}$ solution. The diameter of samples is $0.8 \mathrm{~mm}$. Samples with sizes of $2 \mathrm{~cm}$ cut in an SS sheet were prepared degreasing the surfaces with ethanol, and finally dried in open air.

\section{Electrochemical cell}

The experiments were performed in a conventional electrolytic cell $(50 \mathrm{~mL})$ with a platinum counter electrode, using a saturated calomel electrode (SCE) as reference electrode. All reported potentials refer to SCE. The electrodes were immersed in solutions consisting of hydrochloric acid (0.1-0.4 M) with organic inhibitors (penicillin $\mathrm{G}$ ) at concentrations ranging from 20 to $100 \mathrm{ppm}$. The electrochemical cell and the potentiostat/galvanostat Volta lab Model PGZ100 (Radiometer Analytical) were used to test the material. The graphical representation of the electrochemical set up used for the experiments is depicted in Fig. 2.

Commercially available material $\mathrm{Fe}-19 \mathrm{Cr}$ was used as a working electrode specimen. 


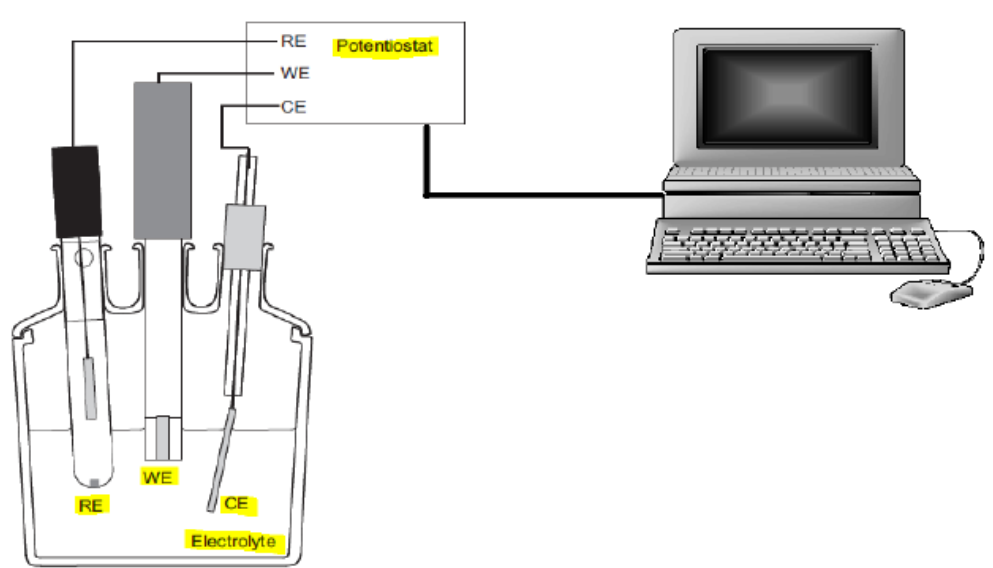

Figure 2. Electrochemical set up for the measurements of open potential and polarization curves.

\section{Electrochemical methods}

The used electrochemical methods are open circuit potential versus time $(V-t)$ and polarization curve $I-V$. They were applied in a system consisting of an electrochemical cell with three electrodes (Fig. 2). Potentiodynamic experiments were conducted using a volt lab PGZ100 controlled with the Voltamaster analysis software. Measurements were conducted under aerated conditions without stirring. At the beginning, the open circuit potential versus time was monitored during $30 \mathrm{~min}$ for each sample, after its immersion in the electrolyte. The electrical potential of the alloy was measured in relation to the reference electrode, and the alloy was just immersed, without applying an electrical current or electrical potential. The potential-time was recorded, and the open circuit potential (EOcp) was determined vs. SCE. The time of 30 min was determined as sufficient after a series of experiments, indicating that the open circuit potential attained the steady state conditions. Then, the sample was submitted to a potential scan (potentiodynamic scan) from $-600 \mathrm{mV}$ to $+600 \mathrm{mV}$, with a $20 \mathrm{mV}$ $\mathrm{s}^{-1}$ sweep rate, referenced to the ECS, and the corresponding current was measured. Finally, the acquisition of the experimental data from the measuring units was automatically carried out via the use of a pc with Voltamaster 4.9 software. Tafel plot was applied to the current potential curve, in order to select some electrochemical parameters - such as the corrosion potential, the corrosion current - and to determine inhibition efficiencies.

\section{Results and discussion}

In the present work, the effect of the presence of Penicillin G molecules near the surface of the alloy $\mathrm{Fe}-19 \mathrm{Cr}$ on the potential time, and the polarization curves response is thoroughly examined. Two important factors - the concentration of the corrosive electrolyte and the inhibitor concentration - vary in this work, which affects more the behavior of the ionic transport to the alloy. 


\section{Effect of electrolyte concentration on corrosion rate}

Open circuit measurements

Open circuit potential is a parameter which indicates the thermodynamically tendency of a material to electrochemical oxidation in a corrosive medium. After a period of immersion it stabilises around a stationary value. This potential may vary with time, because changes in the nature of the surface of the electrode occur (oxidation, formation of the passive layer or immunity). Fig. 3 shows the EOCP (Effect of Open Circuit Potential) curves for all the samples at $295 \mathrm{~K}$.

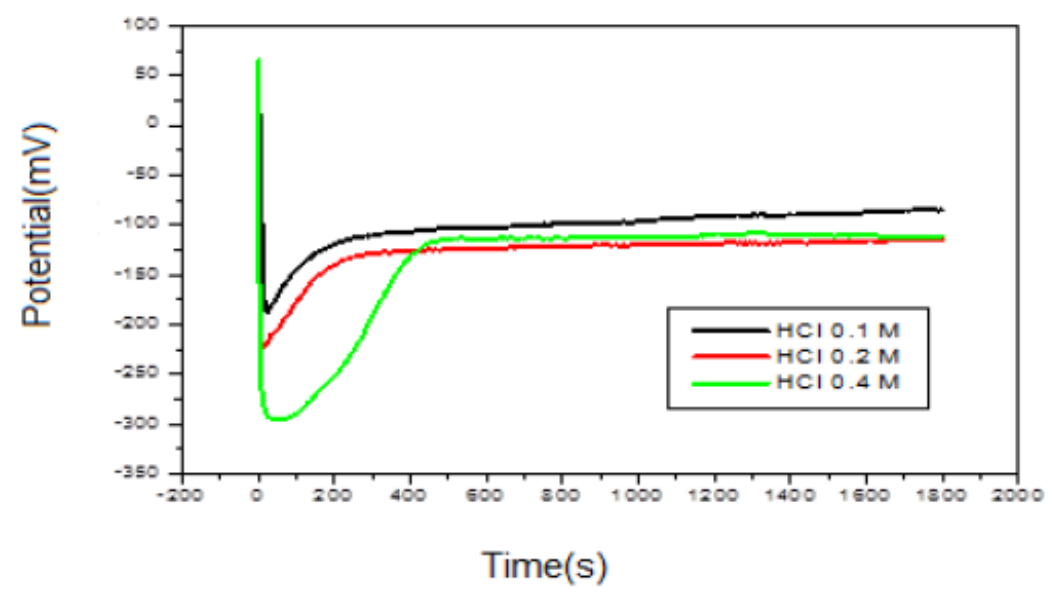

Figure 3. Effect of $\mathrm{HCl}$ concentration on free potential. Fe-19Cr; at $295 \mathrm{~K}$.

As indicated in Fig. 3, the variation of the open circuit potential is similar for all the concentrations. During the first moments of immersion, an abrupt EOCP displacement towards negative potentials occurs, and then it starts to increase, until a stabilized value is reached. This behavior, reported in literature [5], is typical of the reductive dissolution of an oxide film formed in the air, followed by the growth of a new film inside the solution. The EOCP increase seems to be related to the formation and thickening of the oxide film on the metallic surface, improving its corrosion protection abilities. These results suggest that the oxide film formed in all concentrations is the same.

Fig. 3 shows the chrono-potentiometric results of this steel. Open circuit potential versus time was monitored for each sample during 30 min after its immersion in the electrolyte. The first part of the corrosion process was accelerated when the concentration was significant. The stability time increases when the concentration is higher. The stability time is $500 \mathrm{~s}$ for $0.4 \mathrm{M}$, and $200 \mathrm{~s}$ for $0.1 \mathrm{M}$ and $0.2 \mathrm{M}$, approximately. The measurement of free potential allows knowing the immersion time required to establish steady state conditions, which is essential for the measurement of the polarization. However, the measured quantities do not provide information on the kinetics, and do not allow access to the corrosion rate. For that, potentiometer dynamic plots have to be done.

\section{Potentiodynamic curves}

Polarization curves for the material in various concentrations of the $\mathrm{HCl}$ solution are presented in Fig. 4. 
The electrochemical parameters (icorr, Ecorr, $\beta_{\mathrm{a}}, \beta_{\mathrm{c}}$ ) of the system alloy Fe$19 \mathrm{Cr} / \mathrm{HCl}$ at concentration $\mathrm{C}$ are given in Table 1.

The measurements of polarization curves were performed in order to study the corrosion behavior of the alloy and the effect of the concentration on the corrosive media. The corrosion current results obtained by the Tafel plot indicate an increase of the current with the increase on the concentration (Table 1, Fig. 5). The corrosion rate increases with the concentration of the electrolyte, as shown in Fig. 5. The electrochemical behaviour of stainless steel in acidic solutions depends considerably on the concentration of chloride ions and the acidity of the environment [27].

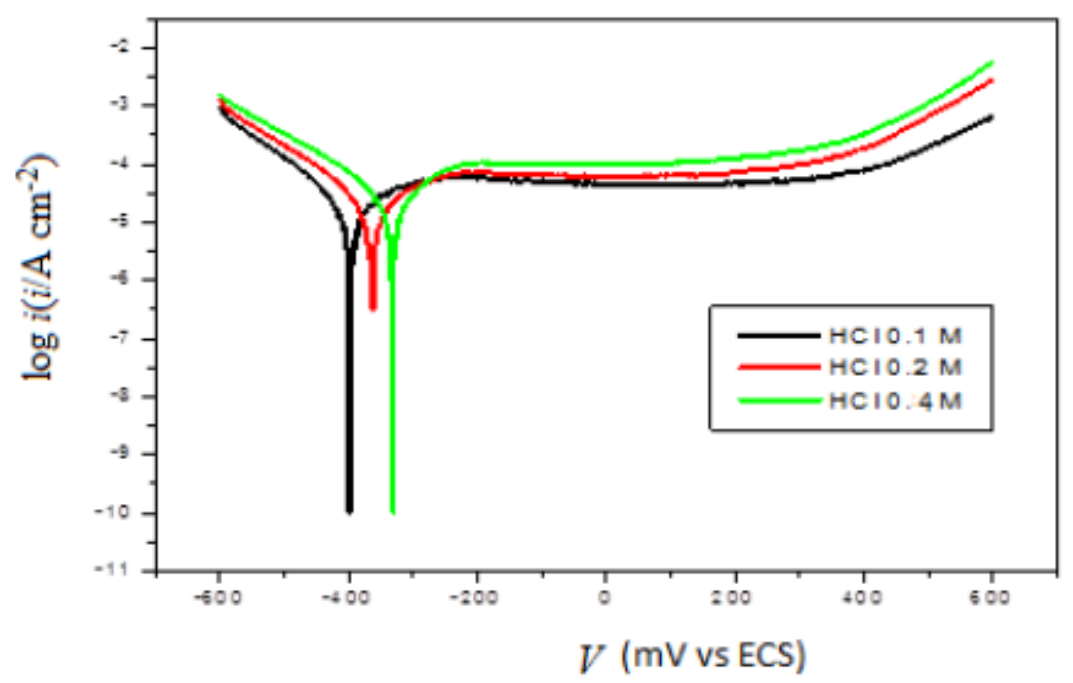

Figure 4. Effect of the $\mathrm{HCl}$ concentration on the polarization curves. $\mathrm{Fe}-19 \mathrm{Cr}$; scan rate $20 \mathrm{mV} \mathrm{s}^{-1} ; 296 \mathrm{~K}$.

Table 1. Corrosion parameters obtained from polarization measurements. The system alloy $\mathrm{Fe}-19 \mathrm{Cr} / \mathrm{HCl}$; scan rate $20 \mathrm{mV} \mathrm{s}^{-1}$; $296 \mathrm{~K}$.

\begin{tabular}{|c|c|c|c|c|c|}
\hline $\begin{array}{c}\text { Concentration of } \mathrm{HCl} \\
\text { solution }(\mathrm{M})\end{array}$ & $\begin{array}{c}\text { icorr } \\
\left(\mu \mathrm{A} \mathrm{cm} \mathrm{cm}^{-2}\right)\end{array}$ & $\begin{array}{c}\text { Ecorr } \\
(\mathrm{mV} \text { vs. SCE) }\end{array}$ & $\begin{array}{c}\boldsymbol{\beta a} \\
\left(\mathbf{m V} \mathbf{d e c}^{-1}\right)\end{array}$ & $\begin{array}{c}\beta c \\
\left(\mathbf{m V ~ d e c}{ }^{-1}\right)\end{array}$ & $\begin{array}{c}C . R \\
(\mu \mathrm{m} / \mathrm{y})\end{array}$ \\
\hline 0.1 & 22.15 & -399.5 & 340.4 & -132.5 & 259.0 \\
\hline 0.2 & 25.30 & -364.9 & 275.8 & -148.5 & 295.9 \\
\hline 0.4 & 31.70 & -333.4 & 132.0 & -164.2 & 370.0 \\
\hline
\end{tabular}

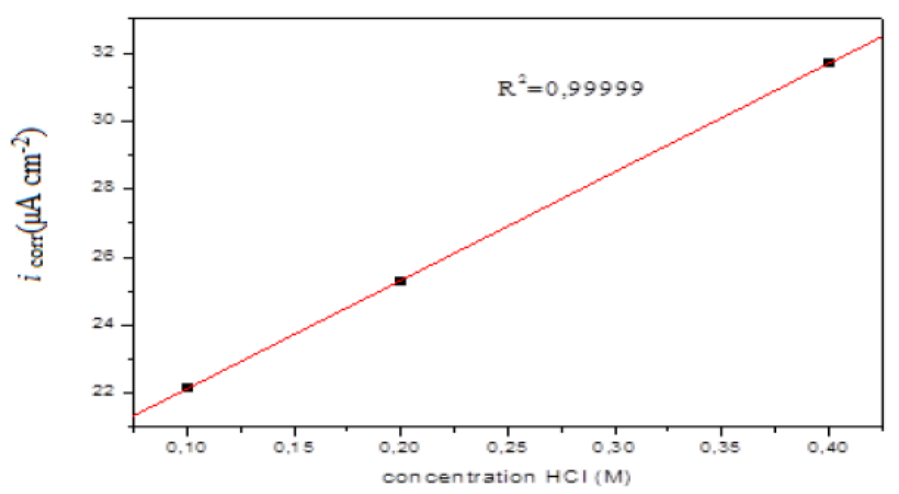

Figure 5. Corrosion rate versus concentration of $\mathrm{HCl}$, Fe-19Cr; $296 \mathrm{~K}$; scan rate $20 \mathrm{mV}$ $\mathrm{s}^{-1}$. 


\section{Calculation of corrosion rate}

All the recorded icorr values (expressed in $\mu \mathrm{A} \mathrm{cm}^{-2}$ ) were converted into the corrosion rate (C.R) in $\mu \mathrm{my}^{-1}$ (Micrometer per year; the penetration rate of corrosion through a metal), using the expression [9, 24-25]:

$$
\text { C.R }=3280.10^{-3} \text { icorr. }(\mathrm{M} / \mathrm{nd}) \cong 11.6 . \text { icorr }
$$

where $\mathrm{M}$ is the atomic weight of $\mathrm{Fe}, \mathrm{n}$ the number of electrons transferred in the corrosion reaction and $\mathrm{d}$ the density of $\mathrm{Fe}$.

\section{The effect of the penicillin $\mathrm{G}$ addition on the corrosion rate of $\mathrm{Fe}-19 \mathrm{Cr}$ alloy Open circuit measurements}

Examples of the open circuit potential versus time curves are depicted in Fig. 6. These curves show two parts. At the first part, the metal corrosion is immersed and then it is passive. The free potential was stabilized at EOCP after $300 \mathrm{~s}$ of immersion. As a general tendency, the system alloys and the solution that contains high content of inhibitors $(100 \mathrm{ppm})$ have the highest free potential $(-390 \mathrm{mV})$, while the same system without inhibitor gives the free potential of $(-410 \mathrm{mV}$ vs. SCE).

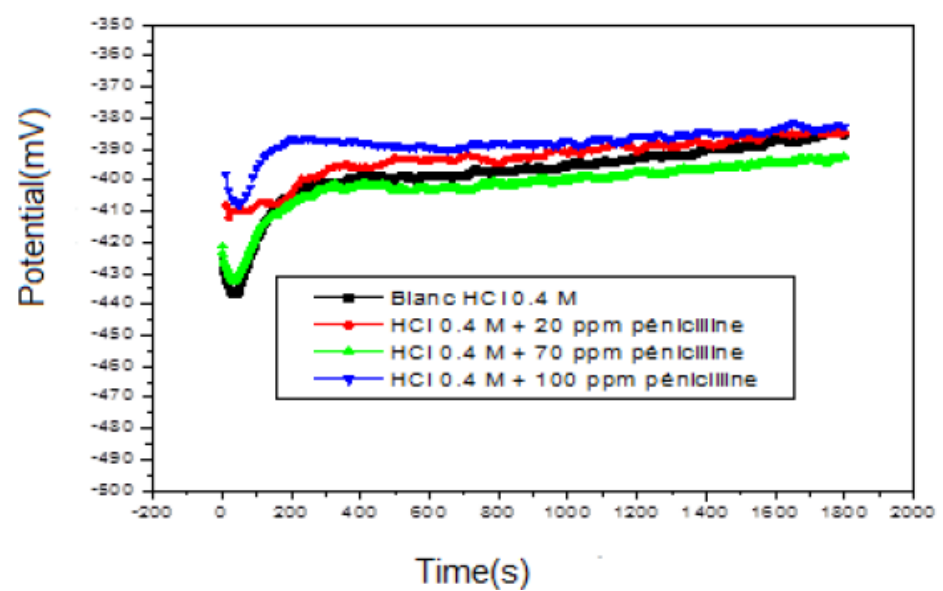

Figure 6. The open circuit or free potential of the dental alloy $\mathrm{Fe}-19 \mathrm{Cr}$ with and without the penicillin $\mathrm{G}$ inhibitor; $298 \mathrm{~K}$.

\section{Potentiodynamic polarization curves}

Fig. 7 shows the cathodic and anodic polarization curves of steel immersed in $0.4 \mathrm{M} \mathrm{HCl}$, in the absence and the presence of different concentrations of the inhibitor at a temperature of $23{ }^{\circ} \mathrm{C}$. As it can be obviously seen from Fig. 7, the addition of penicillin $\mathrm{G}$ to the corrosive media slows down both cathodic hydrogen evolution reactions and anodic dissolution of steel. The corrosion current density and corrosion rate of steel were noticeably reduced in the presence of the inhibitor.

The inhibition of both anodic and cathodic reactions is more distinct with an increasing inhibitor concentration, while the corrosion potential nearly remained 
the same in comparison with the blank solution. These results indicate that penicillin $\mathrm{G}$ can be classified as a mixed type corrosion inhibitor.

Electrochemical corrosion kinetic parameters such as corrosion potential Ecorr, current density icorr, corrosion rate $(C R)$ and cathodic and anodic Tafel slopes $\left(\beta_{\mathrm{c}}\right.$ and $\beta_{\mathrm{a}}$ ) were determined by the analysis of Tafel plot, and they are listed in Table 2 .

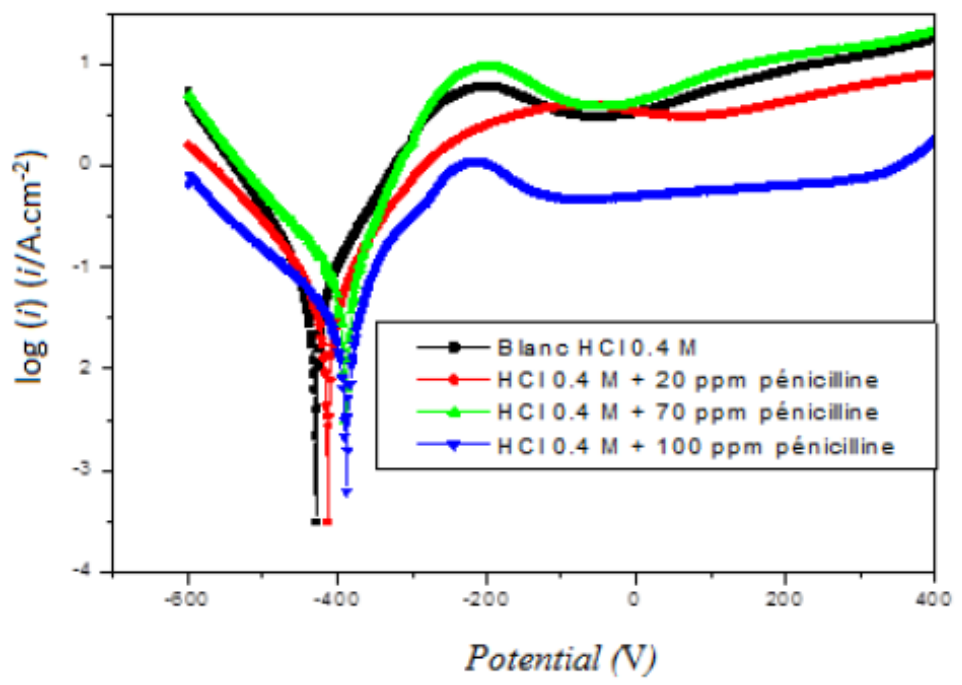

Figure 7. Linear polarization curves on $\mathrm{Fe}-19 \mathrm{Cr}$ electrode in $0.4 \mathrm{M} \mathrm{HCl}$ without and with various concentrations of penicillin $\mathrm{G}$. The scan rate is $50 \mathrm{mV} \mathrm{s}^{-1} ; \mathrm{T}=296 \mathrm{~K}$.

Table 2. The electrochemical parameters and inhibition efficiency for corrosion of Fe$19 \mathrm{Cr}$ in $0.4 \mathrm{M} \mathrm{HCl}$ obtained by polarization method. $\mathrm{T}=296{ }^{\circ} \mathrm{C}$.

\begin{tabular}{|c|c|c|c|c|c|c|c|c|}
\hline $\begin{array}{c}\text { Inhibitor } \\
\text { (penicillin G) } \\
\text { ppm }\end{array}$ & $\begin{array}{c}i \text { corr } \\
\left(\mu \mathrm{A} \mathbf{c m}^{-2}\right)\end{array}$ & $\begin{array}{c}E_{\text {corr }} \\
(\mathrm{mV} \text { vs. SCE) }\end{array}$ & $\begin{array}{c}\beta \mathrm{a} \\
\left(\mathbf{m V} \operatorname{dec}^{-1}\right)\end{array}$ & $\begin{array}{c}\beta c \\
\left(m V \operatorname{dec}^{-1}\right)\end{array}$ & $\begin{array}{c}R_{\mathbf{P}} \\
\left(\Omega \mathrm{cm}^{-2}\right)\end{array}$ & $\begin{array}{c}C R \\
(\mu \mathrm{m} / \mathbf{Y})\end{array}$ & $\theta$ & $\begin{array}{l}I E \\
(\%)\end{array}$ \\
\hline Blank & 73.80 & -432.2 & 87.2 & -95.3 & 268 & 862.6 & --- & --- \\
\hline 20 & 47.55 & -415.9 & 90.3 & -109.6 & 452 & 555.7 & 0.3556 & 35.56 \\
\hline 70 & 40.30 & -391.6 & 54.1 & -100.3 & 378.66 & 470.7 & 0.4539 & 45.39 \\
\hline 100 & 30.00 & -390.9 & 75.5 & -158.0 & 739.43 & 350.6 & 0.5934 & 59.34 \\
\hline
\end{tabular}

Surface coverage $(\theta)$, inhibition efficiency $(I E \%)$ and polarization resistance $\left(R_{\mathrm{p}}\right)$ were calculated and are listed in Table 2. The degree of surface coverage $(\theta)$ and the percentage inhibition efficiency $(I E \%)$ were calculated using the following equations $[15,20,26]$ :

$$
\theta=((i \text { corr }-i \operatorname{corr}(\text { inh })) / i \text { corr }
$$

where $i_{\text {corr }}$ and $i_{\text {corr(inh) }}$ are the corrosion current density in the absence and in the presence of an inhibitor, respectively [12, 13, 20,26].

$$
I E \%=((i \text { corr }-i \text { corr }(\text { inh })) / i \text { corr } \times 100
$$

The values of polarization resistance $(R \mathrm{p})$ were calculated using the Stern-Geary equation $[9,22]$.

$$
R \mathrm{p}=\left(\beta_{\mathrm{a}} \times \beta_{\mathrm{c}}\right) /\left(2.303 \times I \operatorname{corr} \times\left(\beta_{\mathrm{a}}+\beta_{\mathrm{c}}\right)\right)
$$


Use of corrosion inhibition is one of the best available methods to minimize the loss of steel [23]. However, the inhibitor's mechanism is not properly known.

According to Riggs and others $[15,26]$, if the displacement in the corrosion potential Ecorr, for the uninhibited system: i) is higher than $85 \mathrm{mV}$ with respect to Ecorr in the inhibited system, the inhibitor can be seen as of the cathodic or anodic type; ii) is lower than $85 \mathrm{mV}$, the inhibitor can be seen as of the mixed type. The results in Table 2 show that the differences in Ecorr values between inhibited and blank systems are generally less than $85 \mathrm{mV}$, approximately 41 $\mathrm{mV}$, which implies that the studied penicillin $\mathrm{G}$ is a mixed-type inhibitor.

A maximum inhibition efficiency of about $60 \%$ for penicillin $\mathrm{G}$ was achieved at $100 \mathrm{ppm}$. It is clearly observed that penicillin $G$ reduces the corrosion current density, and the suppression in current increases as the inhibitor concentration increases. Corrosion potential is shifted to positive values in the presence of penicillin $G$, but it is not significantly changed with respect to the inhibitor concentrations. $\beta_{\mathrm{a}}$ and $\beta_{\mathrm{c}}$ Tafel slope values are not significantly affected in an inhibited solution as compared to an uninhibited solution. This observation suggests that the inhibitor molecules are adsorbed onto the metallic surface by blocking the active sites on the surface. Organic compounds cannot be specifically designed as anodic or cathodic inhibitors. They are mixed inhibitors that inhibit both anodic and cathodic reactions. The effectiveness of organic inhibitors is related to the extent to which they are adsorbed and cover the metal surface. Corrosion inhibitors effectively eliminate the undesirable destructive effect and prevent metal dissolution.

\section{Adsorption isotherm}

The electrochemical process, which occurs on the metal/solution interface, is greatly influenced by the adsorption of the inhibitor molecules, which is known to depend on the chemical structures. Therefore, adsorption isotherms are very important in determining the mechanism of inhibition. The adsorption of the organic substance (penicillin $\mathrm{G}$ ) at the metal/solution interface may be written according to the following reaction [17]:

$$
\operatorname{Organic}_{(\text {soln })}+n \mathrm{H}_{2} \mathrm{O}_{(\text {ads })} \rightarrow \text { Organic }_{(\text {ads })}+n \mathrm{H}_{2} \mathrm{O}_{(\text {soln })}
$$

where $\mathrm{n}$ is the number of water molecules removed from the metal surface for each molecule of adsorbed inhibitor. Clearly, the value of $n$ depends on how the molecule arranges itself on the surface due to the surface roughness, and on the interaction among molecules. Basic information on the interaction between the inhibitor molecules and the alloy surface can be provided by the adsorption isotherm. To obtain more information about the interaction between the penicillin $\mathrm{G}$ molecules and the electrode surface, the Langmuir adsorption isotherm was investigated. The degree of surface coverage, $\theta$, at different concentrations of the penicillin $G$ in an acid solution, was calculated from the corresponding electrochemical polarization measurements, according to Eq.1 [12-15, 21]. The 
obtained values of $\theta$ are fitted to Langmuir isotherm. The Langmuir isotherm, Eq. 4 , is verified in the case of penicillin G [21]:

$$
K C=\theta /(1-\theta)
$$

where $C$ is the concentration of the inhibitor, $\theta$ the fractional surface coverage and $K$ is the adsorption equilibrium constant. The value of $K$ is related to the free energy of adsorption $\Delta G^{\mathrm{o}}$ ads as $[7,12-13,21]$ :

$$
K=\left(1 / C_{\text {sol }}\right) \times \exp \left(\Delta G_{\text {ads }}^{o} / R T\right)
$$

where $\mathrm{C}_{\text {sol }}$ represents the molar concentration of the solvent - which is $55.5 \mathrm{~mol}$ $\mathrm{L}^{-1}$ in the case of water,$- R$ the universal gas constant and $T$ is the temperature. The mathematical formulation of the Langmuir adsorption isotherm is expressed by:

$$
C_{\mathrm{inh}} / \theta=1 / K+C_{\mathrm{inh}}
$$

The best fitted straight line is obtained for the plot of $C_{\text {inh }} / \theta$ versus $C_{\text {inh }}$ with slopes around unity. This suggests that the adsorption of penicillin $G$ onto the metal surface follows the Langmuir adsorption isotherm (Fig.8). From the intercepts of the straight lines $C_{\mathrm{inh} /} \theta_{-} C_{\mathrm{inh}}, K$ values are calculated, and they are given in Table 3. The most important thermodynamic adsorption parameter is the free energy of adsorption ( $\Delta G^{\mathrm{o}}$ ads). The adsorption constant, $K$, is related to the standard free energy of adsorption, $\Delta G^{\mathrm{o}}$ ads, with the following equation:

$$
\Delta \mathrm{G}^{\mathrm{o}} \mathrm{ads}=-2.3 . \mathrm{RT} \log (55.5 \mathrm{Kads})
$$

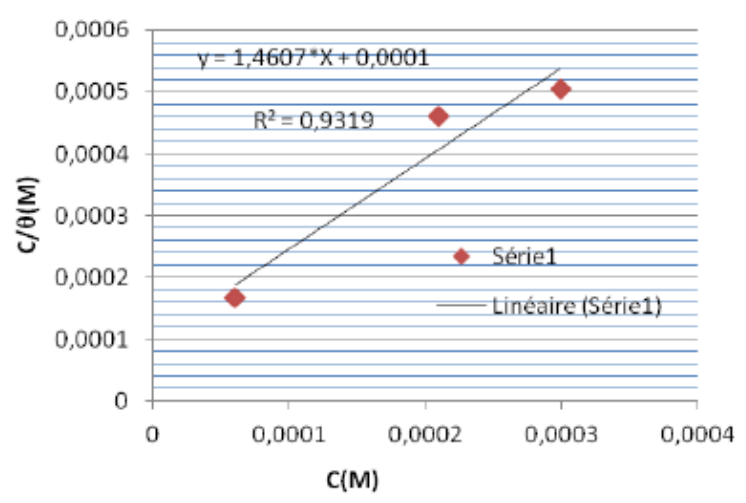

Figure 8. Langmuir adsorption isotherm for penicillin $G$ on $\mathrm{Fe}-19 \mathrm{Cr}$ obtained by Tafel data. $\mathrm{T}=298 \mathrm{~K}$ in acid solution $(0.4 \mathrm{M})$.

Table 3. Thermodynamic parameters of (penicillin G) adsorption on $\mathrm{Fe}-19 \mathrm{Cr}$ at $296 \mathrm{~K}$ and in $0.4 \mathrm{M} \mathrm{HCl}$.

\begin{tabular}{|c|l|l|c|}
\hline \multirow{2}{*}{ System } & \multicolumn{3}{|c|}{ Langmuir isotherm } \\
\cline { 2 - 4 } & $K$ ads $\mathrm{M}^{-1}$ & $\mathrm{R}^{2}$ & $-\Delta G^{\circ}$ ads $\left(\mathrm{kJ} \mathrm{mol}^{-1}\right)$ \\
\hline Peniciline $\mathrm{G}$ & $1.10^{4}$ & 0.93 & 32.72 \\
\hline
\end{tabular}

The value of the free energy of adsorption of penicillin $\mathrm{G}$ on $\mathrm{Fe}-19 \mathrm{Cr}, \Delta G^{\mathrm{o}}$ ads, is found to be $-32.72 \mathrm{~kJ} \mathrm{~mol}^{-1}$. A value of $-40 \mathrm{~kJ} \mathrm{~mol}^{-1}$ is usually adopted as a threshold value between chemi and physisorption [13-14]. The calculated value 
for the adsorption of penicillin $\mathrm{G}$ on the electrode $\mathrm{Fe}-19 \mathrm{Cr}$ indicates that the adsorption is made in a physical way, and there is no chemical interaction between the inhibitor molecule and the metal surface. The adsorption of penicillin $\mathrm{G}$ obeys the Langmuir isotherm, and the negative values of Gibbs energy indicate the nature of interactions between the inhibitor molecules and the metal surface.

Eddy et al. [14], who pioneered research in the field of penicillin as a mild steel corrosion inhibitor, explained the inhibitory action of penicillin $\mathrm{G}$ and penicillin $\mathrm{V}$ in terms of their physical adsorption onto the surface of mild steel. It was proposed that the adsorption of penicillin onto the mild steel surface is controlled by weak intermolecular interactions. Actually, the strength of interaction between penicillin and the steel surface was always variable and dependent on the adsorption on active sites. Alder et al. [16] confirmed that penicillin is especially influenced by $\mathrm{pH}$, due to the fast degradation of the chemically unstable lactam ring. As a consequence, the adsorption of penicillin $G\left(\Delta G_{\text {ads }}^{\mathrm{o}}=-9.65 \mathrm{~kJ} \mathrm{~mol}^{-1}\right)$ onto mild steel in acidic media has been found considerably different from that of the parent compound, and in case of penicillin $\mathrm{V}$, even lower $\left(\Delta G_{\text {ads }}^{\mathrm{o}}=-15.91 \mathrm{~kJ}\right.$ $\left.\mathrm{mol}^{-1}\right)$. This was attributed to the presence of amino and carbonyl functional groups, as well as of nitrogen and sulfur atoms in the aromatic/cyclic structure. The adsorption depends on the structure of inhibitors [13, 26], on the surface charge of the metal, and on the type of electrolyte [16].

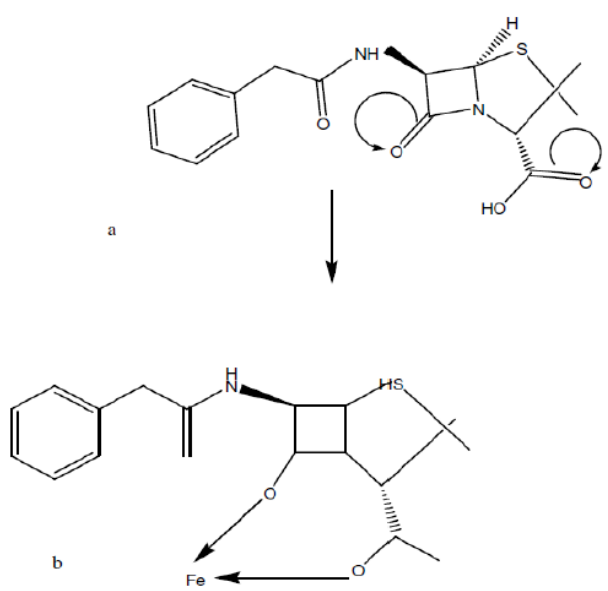

Figure 9. Formation of the complex Fe-penicillin G [14].

\section{The adsorption mechanism}

The study of the mechanism of action of corrosion inhibitors has a great importance on the formulation of new inhibitors and for the correct use of these inhibitors under different conditions. In many industrial operations, like pickling and acid cleaning, the choice of optimum working conditions and process duration is of particular importance. The used inhibitors have to be chemically stable, and to provide high protective effect under the applied conditions.

The inhibiting effect for pickling must be higher than for water-supply systems in the approximate ratio of 2 [21]. The electrochemical process which occurs on the metal-aggressive solution interface is greatly influenced by the adsorption of the inhibitor molecules, and the chemical structures influence the adsorption. The 
molecular structure of penicillin shown on Fig. 1 contains hetero atoms $(\mathrm{N}, \mathrm{S})$, which increase its inhibition efficiency. In acidic media, penicillin $G$ can be hydrolyzed, which produces anhydrous penicillin G (Fig. 9).

This compound contains free electrons that can be donated to the vacant d-orbital of Fe in mild steel, leading to the formation of a complex that protects the metal against corrosion. N.O. Eddy et al. [14] proposed the adsorption mechanism of penicillin $\mathrm{G}$ on metal (Fe). This mechanism is shown in Fig. 9. The adsorption of the inhibitor onto the metal surface can be facilitated by the presence of heteroatoms (such as $\mathrm{N}, \mathrm{O}, \mathrm{P}$ and $\mathrm{S}$ ), as well as by the aromatic ring. The inhibition of the metal corrosion can also be viewed as a process that involves the formation of chelate on the metal surface, which involves the transfer of electrons from the organic compounds to the metal surface, and the formation of a coordinate covalent bond. In this case, the metal acts as an electrophile, while the nucleophilic centre is in the inhibitor.

\section{Conclusions}

In the present work, electrochemical methods were used to study the ability of penicillin $\mathrm{G}$ compounds to inhibit the corrosion of $\mathrm{Fe}-19 \mathrm{Cr}$ in aerated $\mathrm{HCl}$ solutions. The principal conclusions are the following:

- The system alloys and the solution that contains a high content of inhibitors (100 ppm) have the highest open circuit potential $(-390 \mathrm{mV})$, while the same system without inhibitor gives the free potential (-410 mV vs. SCE).

- The galvanostatic polarization curve indicated that the penicillin $\mathrm{G}$ compound inhibited both anodic metal dissolution and cathodic hydrogen evolution reaction. This compound acted as a mixed type inhibitor.

- It was found that the corrosion current density obtained by the Tafel plot of the polarization curve of $\mathrm{Fe}-19 \mathrm{Cr}$ in $0.4 \mathrm{M} \mathrm{HCl}$ is $73.80 \mu \mathrm{A} \mathrm{cm} \mathrm{cm}^{-2}$, while the current density is $47.55 \mu \mathrm{A} \mathrm{cm}^{-2}$, when $20 \mathrm{ppm}$ of penicillin $\mathrm{G}$ are added. It was also found that increasing the concentration of the inhibitor leads to the decrease of the current and of the corrosion rate. In addition, the polarization resistance was found to be important when the inhibitor was added.

- The adsorption of penicillin $\mathrm{G}$ was described by the Langmuir isotherm, and the negative values of Gibbs energy indicate the nature of interactions between the inhibitor molecules and the metal surface. The inhibition efficiency was equal to $60 \%$.

\section{References}

1. Dieter L. Traité des matériaux: Corrosion et chimie de surfaces des métaux 12. Coll Ecole Polytechnique de Lausanne: Press Polytechnique et Universitaire Romandes; 1993.

2. Shreir LL, et al. Corrosion, Corrosion Control. Butterworth H Einemann; 1995. Vol 2. 
3. Rahman S, Divi S, Chandra D, et al. Effect Of Different Salts On The Corrosion Properties Of Friction Type A607 Steel Rock Bolt In Simulated Concentrated Water. Tunn Undergr Sp Tech. 2008;23:655-673.

4. Pourbaix M. Atlas Electrochimique. Paris : Gauthier-Villars ; 1963.

5. Manaranche C, Hornberger H. A proposal for the classification of dental alloys according to their resistance to corrosion. Dent Mater. 2007;23:1428-1437.

6. Duff GS, Farinab SB. Corrosion behaviour of a dental alloy in some beverages and drinks. Mater Chem Phys. 2009;115:235-238

7 Bouakkaz S. Le Comportement Electrochimique De L'acier Fe-19Cr, Dans Différents Milieux Aqueux, L'efficacité de l'inhibition de la Pénicilline G. Université -Batna, Algerie ; 2012.

8 Fiaud C. Inhibiteurs de corrosion, Dossier techniques de l'ingénieur l'expertise technique et scientifique de référence. 2012. cor1005.

9 Gabrielli C, Takenouti H. Méthodes electrochimiques appliquées a la corrosion, Techniques de l'ingénieur. Cor 810.

10 Al-Mayout AM, Al-Suhybani AA, Al-Ameery AK. Corrosion inhibition of 304SS in sulfuric acid solutions by 2-methyl benzoazole derivatives. Desalination. 1998;116: 25-33

11 Kesavan D, Gopiraman M, Sulochana N. Green inhibitors for corrosion of metals: A review. Chem Sci Rev Lett. 2012;1:1-8.

12 Benchikh A, Aitout R, Makhloufi L, et al. Soluble conducting poly (anilineco-orthotoluidine) copolymer as corrosion inhibitor for carbon steel in $3 \%$ $\mathrm{NaCl}$ solution. Desalination. 2009;249: 466-474.

13 Issaadi S, Douadi T, Zouaoui A, et al. Novel thiophene symmetrical Schiff base compounds as corrosion inhibitor for mild steel in acidic media. Corros Sci. 2011;53:1484-1488.

14 Eddy NO, Odoemelam SA, Ekwumemgbo P. Inhibition of the corrosion of mild steel in $\mathrm{H}_{2} \mathrm{SO}_{4}$ by penicillin G. Sci Res Essays. 2009;4:33-38.

15 Kumar HS, Karthikeyan S. Inhibition of mild steel corrosion in hydrochloric acid solution by cloxacillin drug. J Mater Environ Sci. 2012;3:925-934.

16 Gece G. Drugs: A review of promising novel corrosion inhibitors. Corros Sci. 2011;53: 3873-3898.

17 Kumar ASL, Iniyavan P, Kumar S, et al. Corrosion Inhibition Studies of Ecbolium Viride Extracts on Mild Steel in HCl. J Mater Environ Sci. 2012;3:670-677.

18 Abdel-Gaber AM, Abd-El-Nabey BA, Khamis E, et al. A natural extract as scale and corrosion inhibitor for steel surface in brine solution. Desalination. 2011;278:337-342.

19 Eddy NO. Experimental and theoretical studies on some amino acids and their potential activity as inhibitors for the corrosion of mild steel, part 2. J Adv Research. 2011;2:35-47.

20 Bommersbach P, Alemany-Dumont C, Millet JP, et al. Formation and behaviour study of an environment-friendly corrosion inhibitor by electrochemical methods. Electrochim Acta. 2005;51:1076-1084. 
21 Helal NH, El-Rabiee MM, Abd El-Hafez GhM, et al. Environmentally safe corrosion inhibition of $\mathrm{Pb}$ in aqueous solutions. J Alloy Comp. 2008;456:372-378.

22 Gece G, Bilgiç S. A theoretical study on the inhibition efficiencies of some amino acids as corrosion inhibitors of nickel. Corros Sci. 2010;52:34353443.

23 Vinutha MR, Venkatesha TV. Review on Mechanistic Action of Inhibitors on Steel Corrosion in Acidic Media. Port Electrochim Acta. 2016;34:157184.

24 Brett C, Brett AM. Electrochemistry principles methods and applications. Oxford: Oxford University Press; 1994.

25 Fontana MG, Grene ND. Corrosion engineering. 2nd ed. New York: McGraw- Hill; 1978.

26 Eddib A, Hamdani M. Electrochemical Studies of Ampicillin as Corrosion Inhibitor for Stainless Steel in Hydrochloric Acid Solution. Mor J Chem. 2014;2:165-175.

27 Albrimi YA, et al. Electrochemical Behaviour of AISI 316 Austenitic Stainless Steel in Acidic Media Containing Chloride Ions. Int J Electrochem Sci. 2011;6:4614-4627. 